\title{
The 'AbdoMAN': an artificial abdominal wall simulator for biomechanical studies on laparotomy closure techniques
}

\author{
L. F. Kroese ${ }^{1}$ J. J. Harlaar ${ }^{2}$ C. Ordrenneau ${ }^{3}$ J. Verhelst ${ }^{1}$ - G. Guérin ${ }^{3}$ \\ F. Turquier $^{3} \cdot$ R. H. M. Goossens ${ }^{4} \cdot$ G.-J. Kleinrensink ${ }^{5} \cdot$ J. Jeekel ${ }^{5}$. \\ J. F. Lange ${ }^{1}$
}

Received: 3 October 2016/ Accepted: 4 April 2017/Published online: 20 April 2017

(c) The Author(s) 2017. This article is an open access publication

\begin{abstract}
Purpose Incisional hernia remains a frequent complication after abdominal surgery associated with significant morbidity and high costs. Animal and clinical studies have exhibited some limitations. The purpose of this study was to develop an artificial human abdominal wall (AW) simulator in order to enable investigations on closure modalities. We hypothesized that a physical model of the human AW would give new insight into commonly used suture techniques representing a substantial complement or alternative to clinical and animal studies.

Methods The 'AbdoMAN' was developed to simulate human AW biomechanics. The 'AbdoMAN' capacities include measurement and regulation of intra-abdominal pressure (IAP), generation of IAP peaks as a result of muscle contraction and measurements of AW strain patterns analyzed with 3D image stereo correlation software. Intact synthetic samples were used to test repeatability. A
\end{abstract}

Electronic supplementary material The online version of this article (doi:10.1007/s10029-017-1615-x) contains supplementary material, which is available to authorized users.

\section{F. Kroese}

1.kroese@erasmusmc.nl

1 Department of Surgery, Erasmus University Medical Center, Rotterdam, The Netherlands

2 Department of Surgery, VU University Medical Center, Amsterdam, The Netherlands

3 Medtronic, Trévoux, France

4 Department Industrial Design Engineering, University of Technology, Delft, The Netherlands

5 Department of Neuroscience, Erasmus University Medical Center, Rotterdam, The Netherlands laparotomy closure was then performed on five samples to analyze strain patterns.

Results The 'AbdoMAN' was capable of simulating physiological conditions. AbdoMAN lateral muscles contract at $660 \mathrm{~N}$, leading the IAP to increase up to $74.9 \mathrm{mmHg}$ (range 65.3-88.3). Two strain criteria were used to assess test repeatability. A test with laparotomy closure demonstrated closure testing repeatability.

Conclusions The 'AbdoMAN' reveals as a promising enabling tool for investigating AW surgery-related biomechanics and could become an alternative to animal and clinical studies. 3D image correlation analysis should bring new insights on laparotomy closure research. The next step will consist in evaluating different closure modalities on synthetic, porcine and human AW.

Keywords Abdominal wall - Biomechanics - Incisional hernia $\cdot$ Laparotomy closure

\section{Introduction}

Incisional hernia is a common complication after abdominal surgery, especially after open surgery with a median laparotomy. Incidences of incisional hernia and burst abdomen after midline laparotomy range from 11 to $20 \%$ and 1 to $3 \%$, respectively, and involve frequent reoperation $[1,2]$. These complications occur even more often in highrisk populations, like patients with comorbidities such as obesity, smoking or diabetes [1-3] and are associated with discomfort or pain, which result in a lower quality of life [4]. In the USA, over 300,000 hernia operations are performed annually, with estimated associated costs of $\$ 3.2$ billion [5]. Mesh-based and suture-based repair of incisional hernia exhibits recurrence rate from 0.8 to $24 \%$ and 
from 12 to $67 \%$, respectively [6-8]. Because most studies provide only short-term follow-up, these recurrence rates may be underestimated.

To prevent incisional hernia, laparotomy closure techniques have frequently been investigated in both experimental and clinical studies. Some of these showed that incisional hernia is an early complication after closure [9]. Several decades of research led to recommend continuous suture technique with small suture bites of $5 \mathrm{~mm}$ from the wound edge and an inter-stitch distance of $5 \mathrm{~mm}$ with slowly absorbable suture material as the most efficient closure technique compared to the commonly used large bites [2, 10-15]. The small bites suture technique still exhibits $13 \%$ incidence incisional hernia at 1 year [15]. Incisional hernias remain a clinical challenge. Both biological and biomechanical mechanisms that result in the occurrence of an incisional hernia remain globally unknown.

Therefore, further research should be conducted to develop and systematically investigate closure techniques and materials. Clinical studies will give the highest level of evidence, but are expensive and in most cases not suitable to investigate new concepts. Preclinical experiments with cadaveric or animal specimens face several problems: the availability of human cadaveric tissue is limited and animal experiments tend to be more and more debated from an ethical standpoint. Moreover, the anatomy and physiology of animals are considerably different from the human ones. For example, the linea alba of a rat is relatively narrow and relatively much shorter compared to the human linea alba [16]. The pig abdominal wall (AW) is more comparable to the human AW, but still exhibits numerous anatomical differences.

Previous research has focused on linear tensile strength testing of sutured porcine AW [12]. Although this research provided important conclusions for further clinical investigation [15], linear testing does not take into account the intra-abdominal pressure acting as well on the AW.

Moreover, linear testing features a flat and not a curved AW and therefore does not mimic the real physiology.

There is a strong need for a standardized way to compare different closure techniques and materials under physiological conditions. This device could be used to investigate pathophysiology and treatment of AW incisional hernia. A standardized artificial AW simulator could also be used as a training device for mechanical evaluation.

The recent study published by Deerenberg et al. [15] clearly shows the impact of mechanical conditions of midline laparotomy closure on clinical outcomes.

The aim of this study was to develop a physical simulator to investigate the mechanical behavior of the AW under physiological conditions using 3D image stereo correlation and to demonstrate the possibility to describe the biomechanics of the AW after laparotomy closure. These experiments will provide a proof of concept of the 'AbdoMAN' device.

\section{Methods}

To simulate human AW biomechanics, the 'AbdoMAN' (Fig. 1) was developed. The 'AbdoMAN' consists of several components which simulate the AW biomechanics. Two main factors had to be taken into account: the intraabdominal pressure and the effect of AW muscle contractions.

\section{Intra-abdominal pressure}

Basal resting intra-abdominal pressure (IAP) varies between 2 and $17 \mathrm{mmHg}$ under normal physiological circumstances [17-19], but can increase up to $20 \mathrm{mmHg}$ in patients suffering from ileus [20]. To simulate the abdominal contents, a 3.5-L air-filled Vacufix ${ }^{\circledR}$ collecting bag (B. Braun, Melsungen, Germany) was used. This pillow was placed on a 3D-printed part, shaped like the AW geometry. A laparoscopic insufflator (Karl Storz, Schaffhausen, Switzerland) was used to regulate the basal pressure level in the pillow.

IAP was measured and recorded in the air pillow using a 0.35 bar pressure sensor (Measurement specialties, Hampton, VA, USA). As in the physiological human situation, the IAP was achieved by the combination of a basal IAP and IAP peaks caused by muscles contractions.

\section{Abdominal wall muscle simulation}

The external, internal oblique and transverse abdominal muscles are situated laterally to the rectus abdominal muscle and their fascias surround the rectus abdominal muscle joining together in the linea alba. These lateral muscles contribute in generating perpendicular force on the linea alba. Those forces can be summated into one force vector. This force can be split in a perpendicular force to the linea alba and a force in craniocaudal direction [21].

Pneumatic actuators (type DMSP, Festo Technology Group, Hauppauge, NY, USA) were used to simulate the muscle contraction. These actuators have the capacity to mimic the contraction of antagonistic muscles. Highstrength fibers provided a relation between raising the internal pressure which resulted in expansion in peripheral direction and decreasing its size in longitudinal direction. Three identical pneumatic actuators, activated synchronously, were placed on both lateral sides, contracting simultaneously (Fig. 1b). 


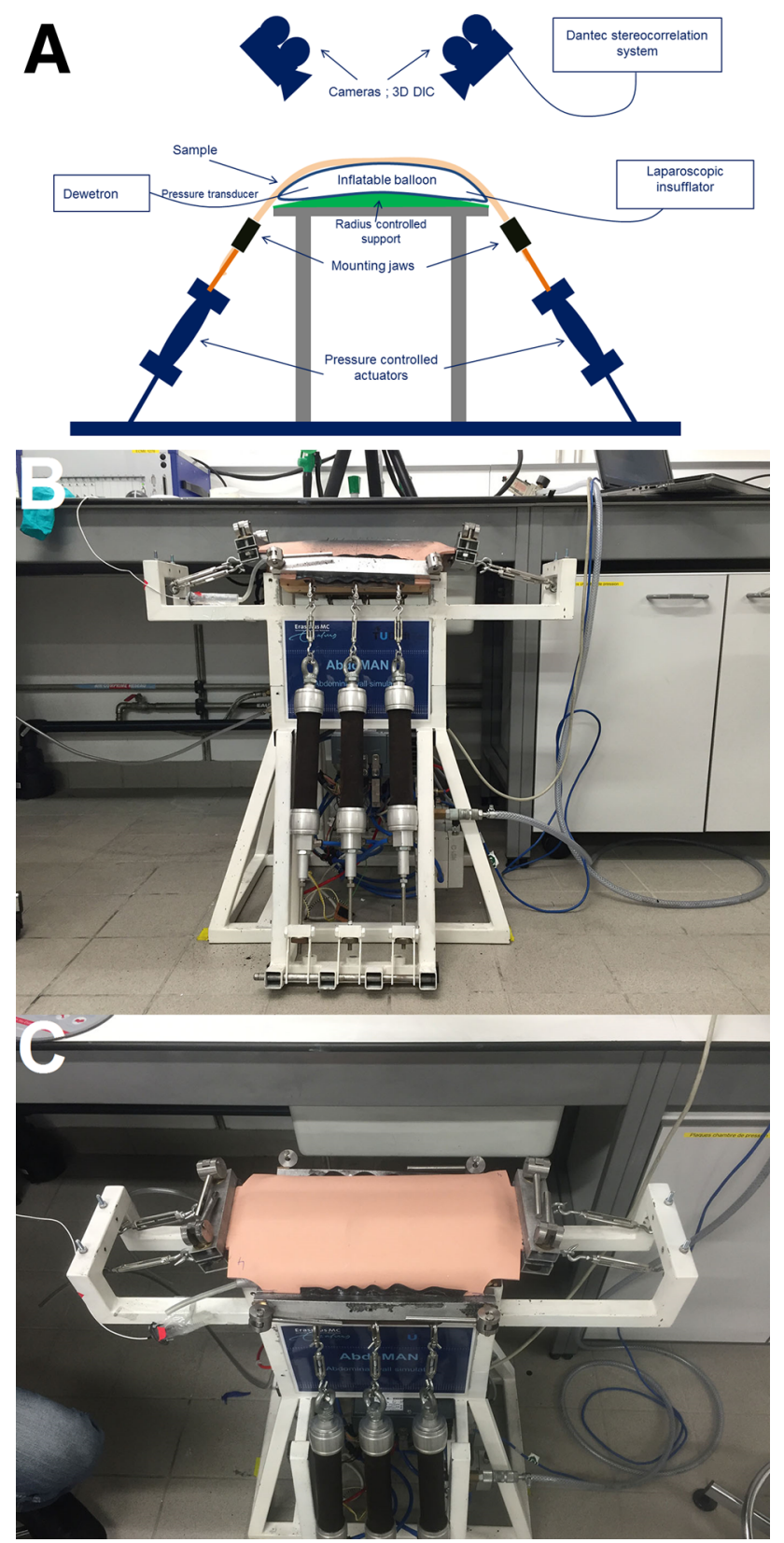

Fig. 1 'AbdoMAN' device. a Schematic overview showing all different components. b Side view showing three lateral muscle actuators connected to the mounted sample and the cranial/caudal jaws used to mount the sample. c Top view showing an intact sample mounted on the 'AbdoMAN' using jaws on all four sides

The AW was fixed on the cranial and caudal sites to mimic the fixation of the rectus abdominis muscle to the rib cage and pubic bone (Fig. 1c).

In the physiological situation, lateral muscles contraction causes a rise in IAP. During activities such as coughing or vomiting, IAP can increase up to 37-81 and $82 \mathrm{mmHg}$ (with peaks of $255 \mathrm{mmHg}$ ), respectively
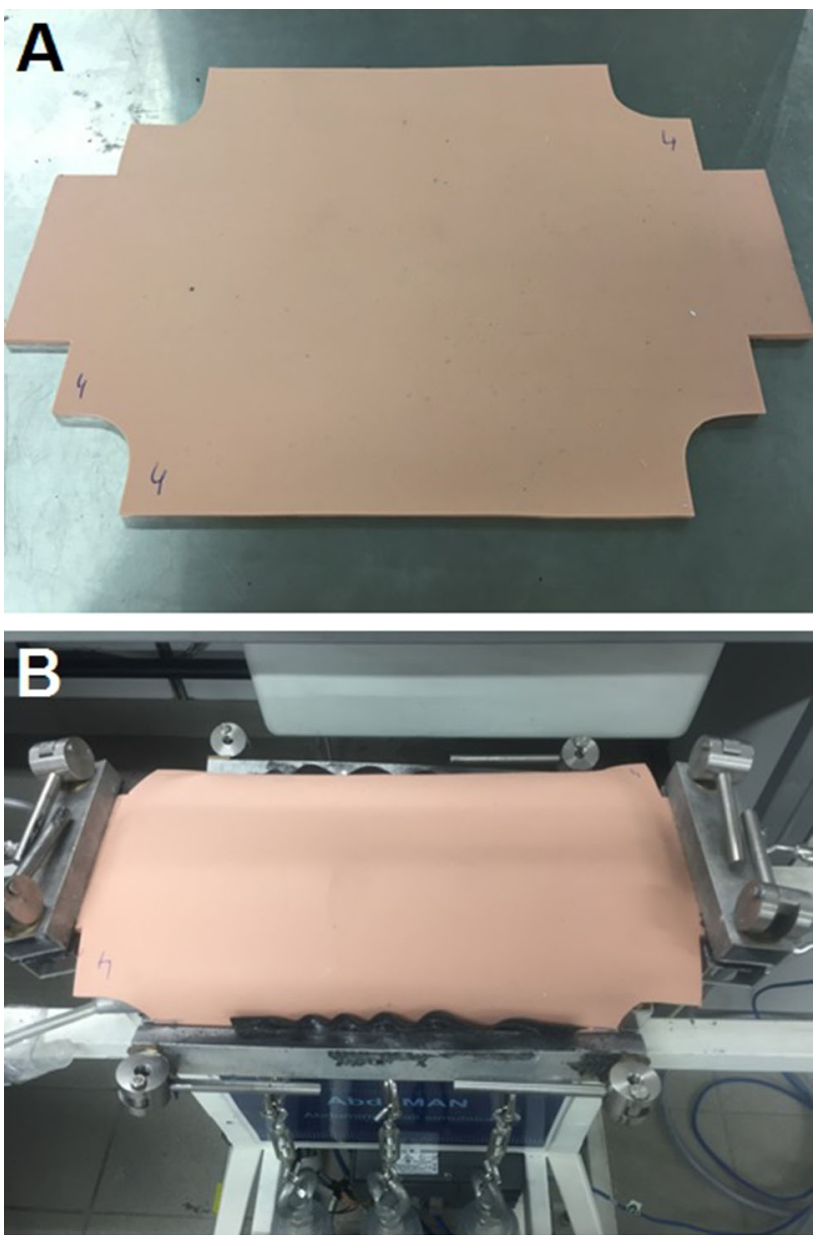

Fig. 2 Abdominal wall samples. a Shape of a sample prior to mounting. b A mounted sample on the 'AbdoMAN' device with fixation in four directions

$[18,19]$. These rises were simulated with the pneumatic actuators and recorded using the pressure sensor connected to the air pillow. To create relevant IAP peaks, the physiological value of the contraction needs to be applied on a sample with material properties close to active human AW. The sample has to be placed on a relevant surrogate of the abdominal content.

\section{Synthetic abdominal wall}

To standardize testing, a custom-made 5-mm-thick synthetic AW, especially made for this study, was used (Fig. 2a). This synthetic material is made of a polyurethane matrix with two layers of elastane fibers (The Chamberlain Group, Great Barrington, USA). A small piece of each synthetic sheet was placed in a tensile testing machine (Instron, High Wycombe, England) to determine the stiffness in two directions [directions 1 (D1) and (D2)]. With 


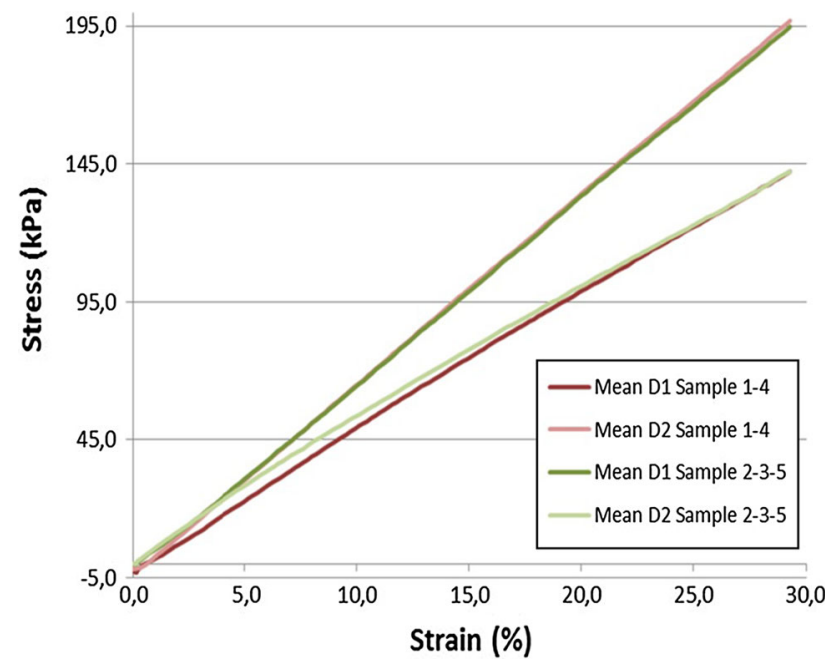

Fig. 3 Synthetic abdominal wall stiffness testing. Each sample was tested in two directions (D1 and D2)

the stiffness of these directions, the anisotropy ratio was calculated. This material has a comparable stiffness compared to the active human AW [22].

Before sample mounting, two PTFE sheets were placed on the AbdoMAN to minimize any possible friction between the sample and the support. AW samples were mounted on the 'AbdoMAN' using clamps to attach the pressure actuators (Fig. 2b). On the cranial and caudal sides, samples were clamped to ensure pretension.

\section{D image stereo correlation}

To capture strain patterns in the artificial AW, 3D image stereo correlation system (Dantec Dynamics, Skovlunde, Denmark) was used. This system captures the 3D displacement and establishes the strain of the tested sample using two cameras and dedicated software. Prior to the test, a black and white paint speckle was applied on the area of interest.

\section{Experimental setup}

\section{Test setup repeatability}

To investigate test reliability and repeatability, pressure and 3D image stereo correlation data were evaluated for a series of synthetic AW samples.

To simulate the physiological conditions, a test setup was chosen with standard IAP of $10 \mathrm{mmHg}$ and to simulate coughing, actuator inner pressure, necessary to generate the lateral muscle force, was increased up to $3000 \mathrm{mmHg}$ during three cycles at $1 \mathrm{~Hz}$ frequency.

\section{Midline closure repeatability}

One of the purposes of this part of the experiment was to investigate the repeatability and the possibilities of visualizing the biomechanical effects of bite size and inter-
Fig. 4 'AbdoMAN' test setup repeatability results. a Synthetic abdominal wall stiffness determined by tensile machine testing of a small piece of each sample. b Peak intra-abdominal pressure during cough cycle of the samples mounted on the 'AbdoMAN'. c Mean strain over surface area of the samples mounted on the 'AbdoMAN'. d Mean strain over transversal line of the samples mounted on the 'AbdoMAN'
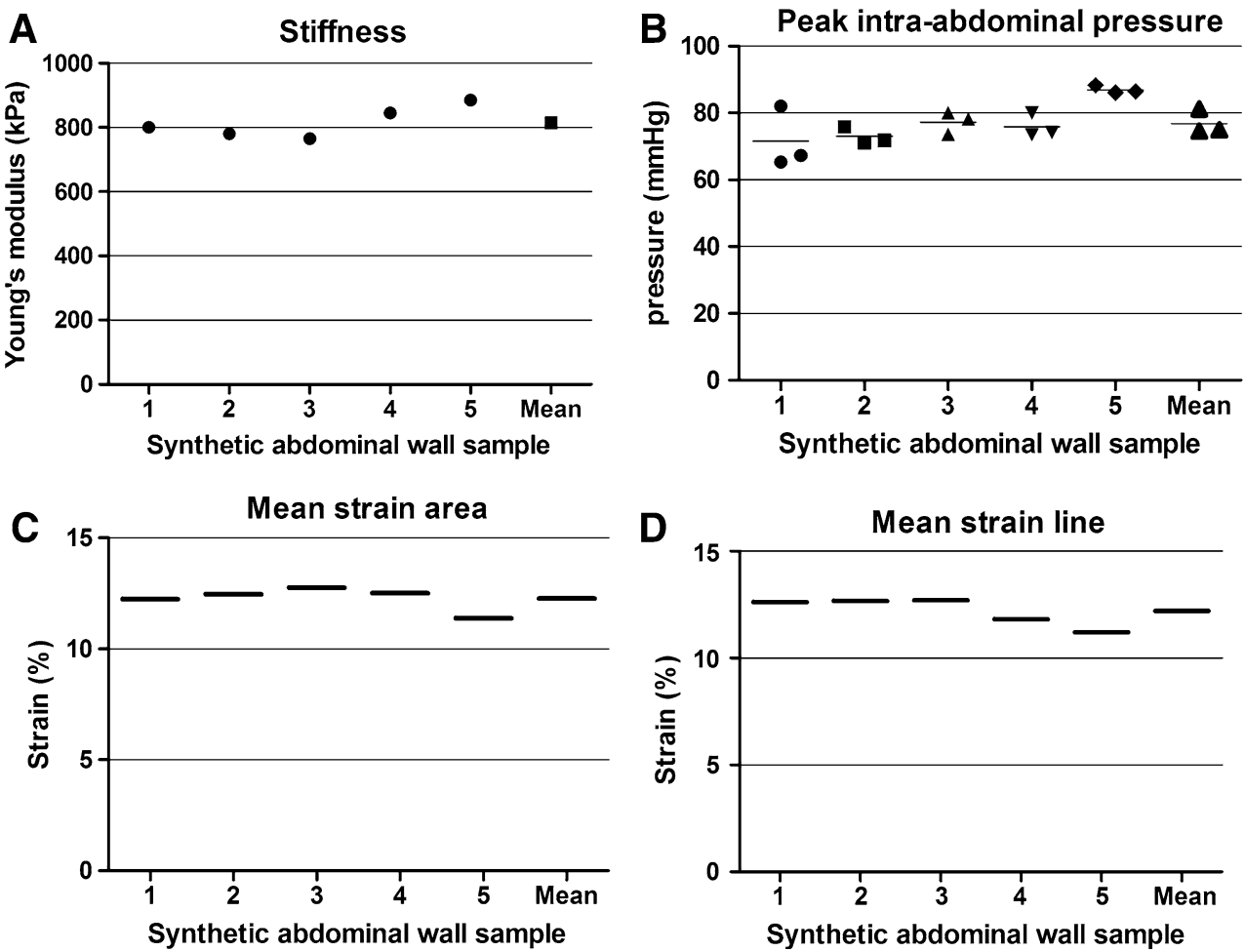
Fig. 5 3D stereo correlation criteria of intact samples.

a Exemplary strain image of an intact synthetic abdominal wall sample at peak intra-abdominal pressure. b Schematic image of used strain analysis areas for 3D stereo correlation: linear strain in the muscle force direction and area strain of a larger surface area

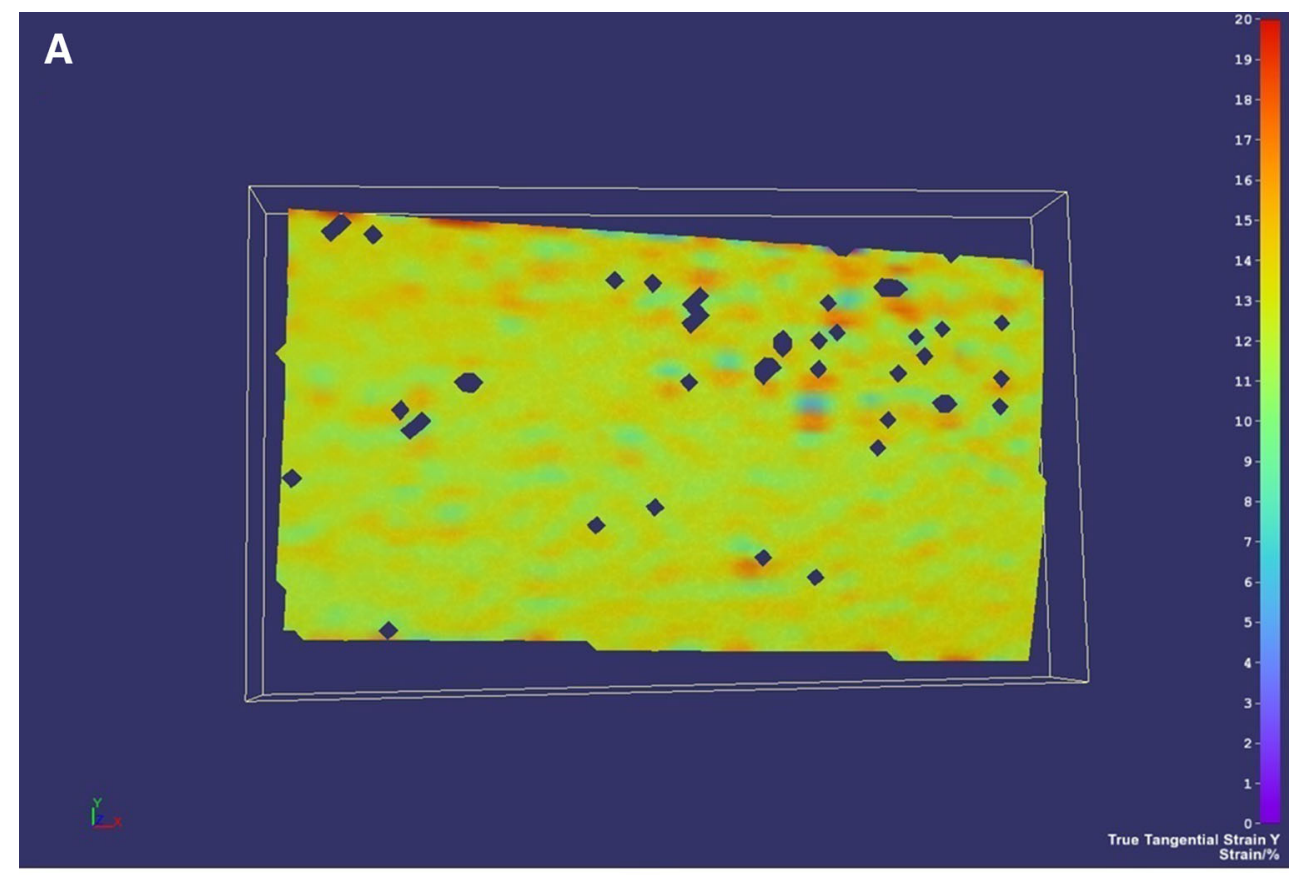

B

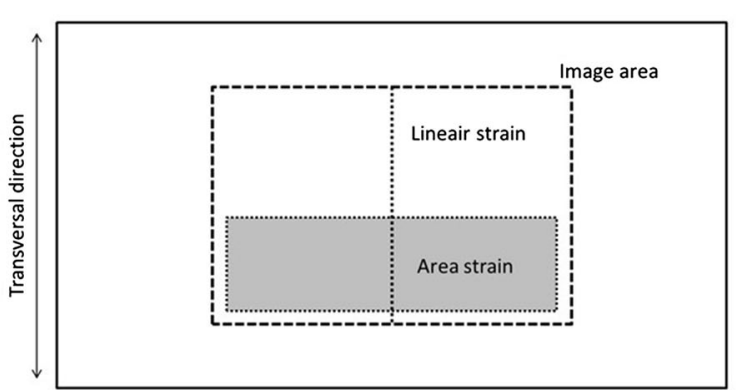

suture distance using 3D image stereo correlation. A $15 \mathrm{~cm}$ median laparotomy was carried out on five synthetic AWs. The incision was closed using PDSII 1 sutures (Ethicon, Somerville, NJ, USA) and using a continuous $5 \times 5$ modality ( $5 \mathrm{~mm}$ distance between suture and incision, $5 \mathrm{~mm}$ distance between two sutures). The suture was knotted five times on both ends. After suturing, the sample was placed on the 'AbdoMAN' and cough tests were performed as described above. Strain patterns and incision distension at the moment of muscle contraction were measured using the $3 \mathrm{D}$ image stereo correlation system to test the reproducibility of sutured samples.

Video material is available as supplemental material online.

\section{Results}

\section{Test setup repeatability}

The stiffness of five synthetic samples was tested in a tensile machine in two directions (D1 and D2). A graph of the synthetic AW stiffness in both directions is shown in Fig. 3. The mean Young's modulus of the stiffest direction was $815 \mathrm{kPa}$ (range $765-885 \mathrm{kPa}$; Fig. 4a) and the mean anisotropic ratio was 1.26 (range 1.22-1.28).

After these tests, samples were mounted on the 'AbdoMAN'. The inner pressure of $3000 \mathrm{mmHg}$ in each pneumatic actuator resulted in a muscle force of 660 Newton $(\mathrm{N})$ (220 N per cylinder) on each lateral side. The length of the sample within the lateral jaws is $28.5 \mathrm{~cm}$ and his thickness is $5 \mathrm{~mm}$. The force is applied on a crosssection of $14.25 \mathrm{~cm}^{2}$, which results in a stress of $0.46 \mathrm{MPa}$.

Fifteen tests were performed using five identical synthetic AWs. The mean IAP peak was $74.9 \mathrm{mmHg}$ (range 65.3-88.3 mmHg; Fig. 4b).

The displacement and strain fields were calculated after each test (Fig. 5). Two criteria were defined to assess the repeatability of the test, the mean transversal strain over an area centered on the sample and the mean transversal strain over a transversal line (Fig. 5b), which exhibited, respectively, $12.27 \%$ (range 11.38-12.75; Fig. 4c) and 12.19\% (range 11.38-12.75; Fig. 4d) of strain. 

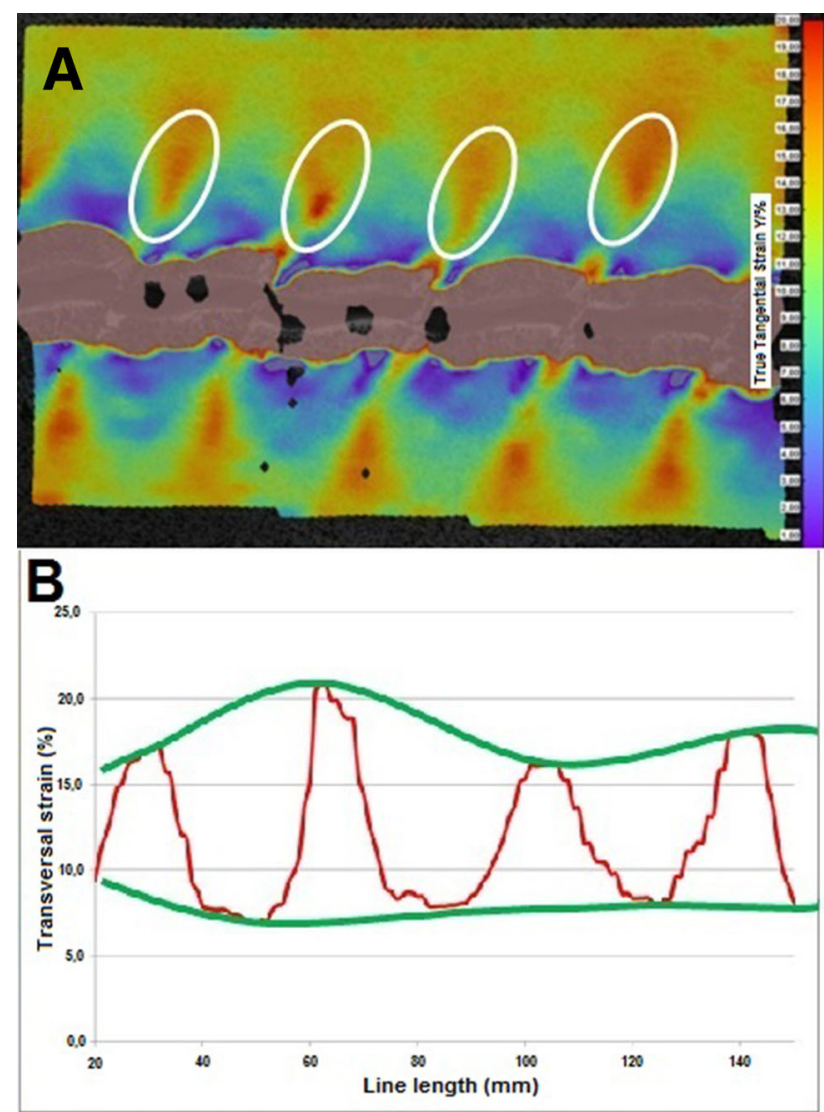

_ Peak-to-peak normalized strain

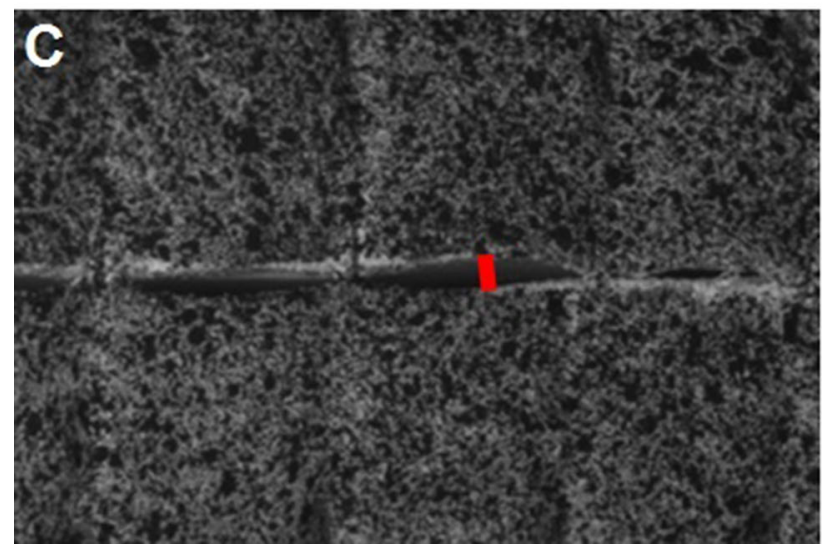

Fig. $63 \mathrm{D}$ stereo correlation criteria of $5 \times 5 \mathrm{~mm}$ suture modality. a Mean maximum strain around suture points. The areas are indicated in the white circles. b Peak-to-peak normalized strain profile through the suture points. Maximum and minimum peaks are indicated and connected with the green lines. c Maximum opening length of the incision. This is indicated with the red line

\section{Midline closure repeatability}

Five incised samples were closed with a $5 \times 5 \mathrm{~mm}$ modality, resulting in a mean suture length to wound length ratio of 6.02 (range 5.88-6.17). No suture breaks were observed. Three comparison criteria between suture modalities were defined based on the analysis of the displacement and strain field of this configuration (Fig. 6):

- Mean maximum strain around suture points. This area surrounds the place where the suture perforates the tissue. This area was used as an area of interest, because maximum force is brought upon this area. These strain areas are indicated in Fig. 6a. The testing of five samples resulted in a mean value of $13.76 \%$ (range 11.7-15.1; Fig. 7a).

- Strain profile through suture points along the incision line.A line was drawn passing through all suture points. The strain profile was used as a result to compare each configuration.

- Peak-to-peak normalized strain profile through the suture points. Figure $6 \mathrm{~b}$ shows the strain on a line, drawn along all points where the sutures perforated the tissue. As can be seen, the strain is the highest around the suture points and the lowest in the area between two suture points. The peak-to-peak normalized strain takes the mean variance between those two extremes. By doing so, attention is not only paid to the absolute value of the strain around the suture points, but also to the strain in relation to its surrounding tissue. The testing of five samples resulted in a mean value of $3.8 \%$ (range 1.3-6.7; Fig. 7b).

- Maximum opening length of the incision. This was defined as the maximum distance between the two sides of the incision, measured during the peak of the muscle contraction (Fig. 6c). The testing of five samples resulted in a mean value of $0.34 \mathrm{~mm}$ (range $0.2-0.5$; Fig. 7c).

\section{Discussion}

The 'AbdoMAN' is the first human AW simulator that enables dynamic testing under physiological conditions. It combines both intra-abdominal pressure (IAP) and abdominal muscle activity.

The stiffness of the synthetic materials $(765-885 \mathrm{kPa})$ is equivalent to an active human AW (600-1000 $\mathrm{kPa}$ ) [23]. The found anisotropic rate of 1.22-1.28 is also in the same order of magnitude as that reported of human linea alba (1.47) [24]. For coughing, the force applied by the pressure actuators, $660 \mathrm{~N}$, and the resulting stress applied on the sample, $0.46 \mathrm{MPa}$, are within the range of the skeletal muscles stress $(0.089-0.801 \mathrm{MPa})$ [18, 19, 25-27]. Mean peak IAP was $74.9 \mathrm{mmHg}$ (range $65.3-88.3 \mathrm{mmHg}$; Fig. $3 b)$ which is entirely in the physiological range of $37-81 \mathrm{mmHg}$ during coughing $[18,19]$. 
Fig. 7 Midline closure repeatability results. a Mean maximum strain around suture points as indicated in Fig. 6a. b Peak-to-peak normalized strain profile through the suture points as indicated in Fig. 6 b. c Maximum opening length of the incision as indicated in Fig. 6c
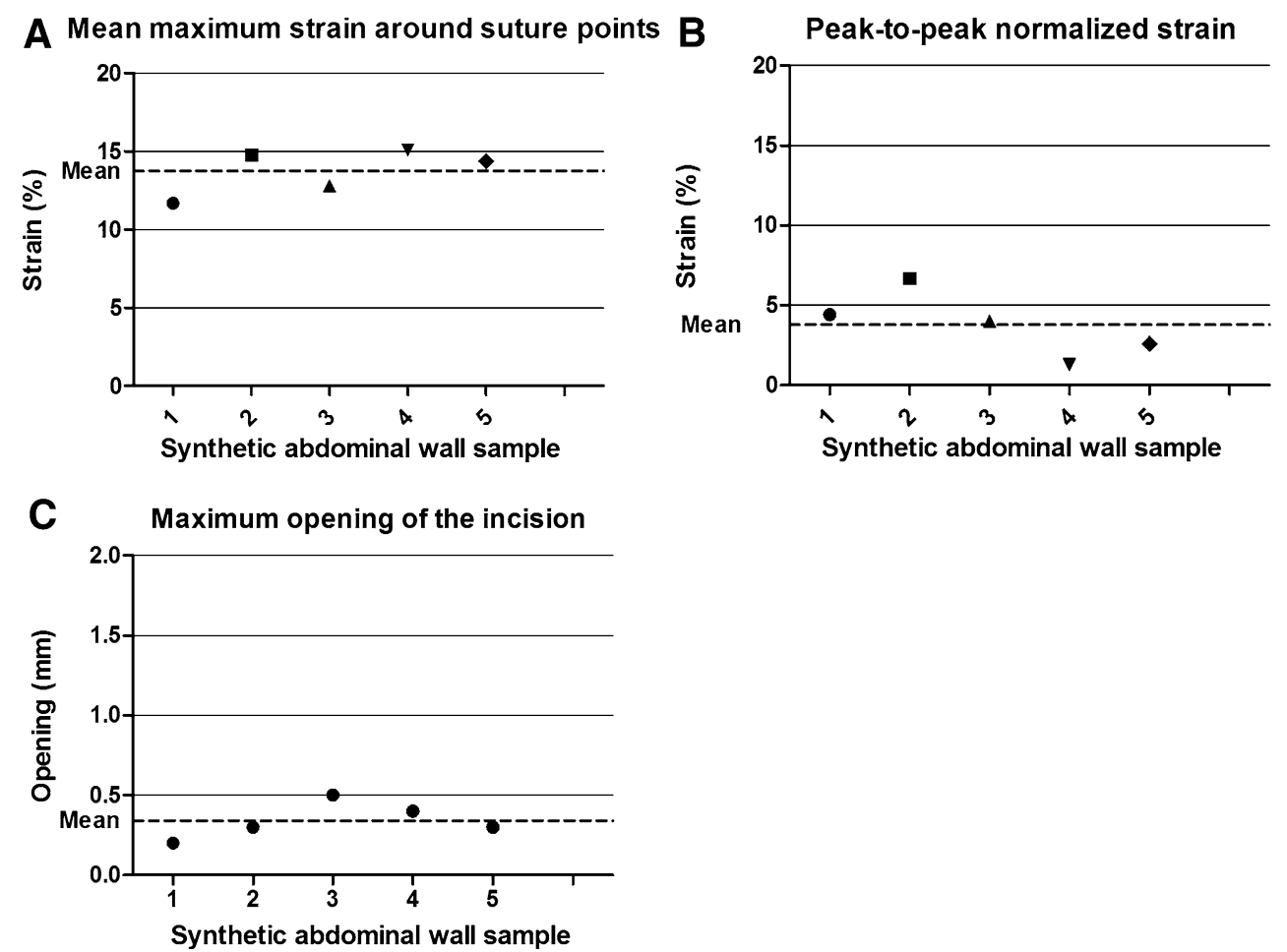

The use of 3D image stereo correlation in combination with a physiological biomechanical simulation model to analyze strain patterns and displacement in AW research was described before [23, 28, 29]. However, the combination with a dynamic simulation device has not been demonstrated yet, and provides insights into the biomechanics of the sutured AW.

The midline closure part demonstrates the possibility to visualize strain patterns around the incision and the suture points. Using a combination of the three criteria described previously, it might be possible to investigate different closure modalities and to find an optimal laparotomy closure modality from a biomechanical standpoint. The criteria used in this part show consistent test results when repeating test cycles with different samples. Therefore, they can be used to compare different suture modalities (i.e., bite sizes).

The next step in this research field will be the systematic testing of different midline closure modalities using both the 'AbdoMAN' and the 3D image stereo correlation system. In the future, human cadaveric AW or porcine $\mathrm{AW}$ could also be used with the 'AbdoMAN' device. For this purpose, additional experiments will be needed to check if the criteria used to compare modalities on synthetic AW will still be relevant using biological tissue.

When this next step has been completed, the 'AbdoMAN' can be used in experiments in which (cough) cycles are being repeated numerous times. This will reflect the physiological situation in which incisional hernias develop over time after a longer period of repeated, intermitting stress.

When more will be known about strain and displacement data interpretation, the 'AbdoMAN' may be used for future research on finding new, ideal suture modalities. Moreover, different suture materials (such as elastic or barbed sutures) or mesh augmentation could be investigated using the 'AbdoMAN'. Even more challenging and interesting would be the creation and closure (with or without mesh) of AW defects to investigate different treatment modalities.

Finally, the 'AbdoMAN' could provide an easily accessible tool for training of laparotomy closure and hernia repair. For example, the effect of a suboptimal closure technique performed by a trainee could be directly evaluated.

To our opinion, the complete test setup can be reproduced at other sites, enabling standardized, simultaneous experiments or teaching settings throughout one (or more) countries.

The 'AbdoMAN' has limitations. It is not possible to simulate tissue healing, as it is a mechanical simulator.

One other limitation is the fact that in this setup, although the stiffness of the synthetic materials was set up to mimic active tissue, the AW does not reproduce the material properties changes driven by the contraction. This might result in different phenomena.

Also, the synthetic AW consists of two components to provide both the strength and flexibility needed to simulate 
the human AW features. This may react differently than the human linea alba, consisting only of connective tissue. The dimensions of the sample, comparable to a human $\mathrm{AW}$, but five times thicker than a fascia [30], the friction between the sample and the artificial abdominal cavity could as well be limitations.

Some variance was found in IAP and strain data, which might be explained by slight stiffness differences observed between synthetic abdominal walls.

\section{Conclusion}

The 'AbdoMAN' could become a promising alternative to or complement for animal and clinical studies on AW closure techniques. The device showed reliable and repeatable results. A first experiment to analyze laparotomy closure demonstrated the possible application of the 'AbdoMAN' device. Future research will evaluate different closure modalities on both synthetic and human or porcine AW to find out more about the underlying mechanisms that drive the biomechanics of laparotomy closure and incisional hernia repair.

Acknowledgements This study was partially funded by Medtronic, Trévoux, France and part of it was conducted in collaboration with Medtronic, Trévoux, France.

Author contributions LK designed the study, performed experiments, collected, analyzed and interpreted data and wrote the report. JH designed the study, performed device development, interpreted data and wrote the report. CO performed experiments, collected, analyzed and interpreted data and wrote the report. JV designed the study, interpreted data and wrote the report. GG performed experiments, collected, analyzed and interpreted data and wrote the report. FT analyzed and interpreted data and wrote the report. RG performed device development, interpreted data and wrote the report. JJ designed the study, interpreted data and wrote the report. GK designed the study, interpreted data and wrote the report. JL designed the study, interpreted data and wrote the report.

\section{Compliance with ethical standards}

Conflict of interest LK declares no conflict of interest directly related to the submitted work. JH declares no conflict of interest directly related to the submitted work. $\mathrm{CO}$ declares conflict of interest not directly related to the submitted work (Medtronic employment). JV declares no conflict of interest directly related to the submitted work. GG declares conflict of interest not directly related to the submitted work (Medtronic employment). FT declares conflict of interest not directly related to the submitted work (Medtronic employment). RG declares no conflict of interest directly related to the submitted work. JJ declares no conflict of interest directly related to the submitted work. GK declares no conflict of interest directly related to the submitted work. JL declares no conflict of interest directly related to the submitted work.

Ethical approval This study did not need approval from the local ethical committee.
Human and animal rights This article does not contain any studies with human participants or animals performed by any of the authors.

Informed consent For this type of article informed consent is not required.

Funding Supported by Medtronic, Trévoux, France.

Open Access This article is distributed under the terms of the Creative Commons Attribution-NonCommercial 4.0 International License (http://creativecommons.org/licenses/by-nc/4.0/), which permits any noncommercial use, distribution, and reproduction in any medium, provided you give appropriate credit to the original author(s) and the source, provide a link to the Creative Commons license, and indicate if changes were made.

\section{References}

1. Bevis PM, Windhaber RA, Lear PA, Poskitt KR, Earnshaw JJ, Mitchell DC (2010) Randomized clinical trial of mesh versus sutured wound closure after open abdominal aortic aneurysm surgery. Br J Surg 97(10):1497-1502. doi:10.1002/bjs.7137

2. van't Riet M, Steyerberg EW, Nellensteyn J, Bonjer HJ, Jeekel J (2002) Meta-analysis of techniques for closure of midline abdominal incisions. Br J Surg 89(11):1350-1356. doi:10.1046/j. 1365-2168.2002.02258.x

3. Webster C, Neumayer L, Smout R, Horn S, Daley J, Henderson W, Khuri S, National Veterans Affairs Surgical Quality Improvement P (2003) Prognostic models of abdominal wound dehiscence after laparotomy. J Surg Res 109(2):130-137 (pii: S0022480402000975)

4. van Ramshorst GH, Eker HH, Hop WC, Jeekel J, Lange JF (2012) Impact of incisional hernia on health-related quality of life and body image: a prospective cohort study. Am J Surg 204(2):144-150. doi:10.1016/j.amjsurg.2012.01.012

5. Poulose BK, Shelton J, Phillips S, Moore D, Nealon W, Penson D, Beck W, Holzman MD (2012) Epidemiology and cost of ventral hernia repair: making the case for hernia research. Hernia 16(2):179-183. doi:10.1007/s10029-011-0879-9

6. Deerenberg EB, Timmermans L, Hogerzeil DP, Slieker JC, Eilers PH, Jeekel J, Lange JF (2015) A systematic review of the surgical treatment of large incisional hernia. Hernia 19(1):89-101. doi:10. 1007/s10029-014-1321-x

7. Luijendijk RW, Hop WC, van den Tol MP, de Lange DC, Braaksma MM, JN IJ, Boelhouwer RU, de Vries BC, Salu MK, Wereldsma JC, Bruijninckx CM, Jeekel J (2000) A comparison of suture repair with mesh repair for incisional hernia. N Engl J Med 343(6):392-398. doi:10.1056/NEJM200008103430603

8. Burger JW, Luijendijk RW, Hop WC, Halm JA, Verdaasdonk EG, Jeekel J (2004) Long-term follow-up of a randomized controlled trial of suture versus mesh repair of incisional hernia. Ann Surg 240(4):578-583 (discussion 583-575, pii: 00000658-200410000-00003)

9. Burger JW, Lange JF, Halm JA, Kleinrensink GJ, Jeekel H (2005) Incisional hernia: early complication of abdominal surgery. World J Surg 29(12):1608-1613. doi:10.1007/s00268-0057929-3

10. Diener MK, Voss S, Jensen K, Buchler MW, Seiler CM (2010) Elective midline laparotomy closure: the INLINE systematic review and meta-analysis. Ann Surg 251(5):843-856. doi:10. 1097/SLA.0b013e3181d973e4

11. Harlaar JJ, van Ramshorst GH, Jeekel H, Lange JF (2010) Effect of stitch length on wound complications. Arch Surg 145(6):599. doi:10.1001/archsurg.2010.78 (author reply 599-600) 
12. Harlaar JJ, van Ramshorst GH, Nieuwenhuizen J, Ten Brinke JG, Hop WC, Kleinrensink GJ, Jeekel H, Lange JF (2009) Small stitches with small suture distances increase laparotomy closure strength. Am J Surg 198(3):392-395. doi:10.1016/j.amjsurg. 2008.10.018

13. van Ramshorst GH, Klop B, Hop WC, Israelsson LA, Lange JF (2013) Closure of midline laparotomies by means of small stitches: practical aspects of a new technique. Surg Technol Int 23:34-38 (pii: sti23/30)

14. Israelsson LA, Millbourn D (2013) Prevention of incisional hernias: how to close a midline incision. Surg Clin North Am 93(5):1027-1040. doi:10.1016/j.suc.2013.06.009

15. Deerenberg EB, Harlaar JJ, Steyerberg EW, Lont HE, van Doorn HC, Heisterkamp J, Wijnhoven BP, Schouten WR, Cense HA, Stockmann HB, Berends FJ, Dijkhuizen FP, Dwarkasing RS, Jairam AP, van Ramshorst GH, Kleinrensink GJ, Jeekel J, Lange JF (2015) Small bites versus large bites for closure of abdominal midline incisions (STITCH): a double-blind, multicentre, randomised controlled trial. Lancet. doi:10.1016/S01406736(15)60459-7

16. Tsui $\mathrm{S}$, Ellis H (1991) Healing of abdominal incisional hernia in infant rats. Br J Surg 78(8):927-929

17. Gerten KA, Richter HE, Wheeler TL 2nd, Pair LS, Burgio KL, Redden DT, Varner RE, Hibner M (2008) Intraabdominal pressure changes associated with lifting: implications for postoperative activity restrictions. Am J Obstet Gynecol 198(3):306.e301-306.e305. doi:10.1016/j.ajog.2007.09.004

18. Iqbal A, Haider M, Stadlhuber RJ, Karu A, Corkill S, Filipi CJ (2008) A study of intragastric and intravesicular pressure changes during rest, coughing, weight lifting, retching, and vomiting. Surg Endosc 22(12):2571-2575. doi:10.1007/s00464-008-0080-0

19. Cobb WS, Burns JM, Kercher KW, Matthews BD, James Norton $\mathrm{H}$, Todd Heniford B (2005) Normal intraabdominal pressure in healthy adults. J Surg Res 129(2):231-235. doi:10.1016/j.jss. 2005.06.015

20. Gallagher JJ (2010) Intra-abdominal hypertension: detecting and managing a lethal complication of critical illness. AACN Adv Crit Care 21(2):205-219. doi:10.1097/NCI.0b013e3181d94fd5
21. Fernandez JW, Mithraratne P, Thrupp SF, Tawhai MH, Hunter PJ (2004) Anatomically based geometric modelling of the musculoskeletal system and other organs. Biomech Model Mechanobiol 2(3):139-155. doi:10.1007/s10237-003-0036-1

22. Forstemann T, Trzewik J, Holste J, Batke B, Konerding MA, Wolloscheck T, Hartung C (2011) Forces and deformations of the abdominal wall-a mechanical and geometrical approach to the linea alba. J Biomech 44(4):600-606. doi:10.1016/j.jbiomech. 2010.11.021

23. Tran D, Mitton D, Voirin D, Turquier F, Beillas P (2014) Contribution of the skin, rectus abdominis and their sheaths to the structural response of the abdominal wall ex vivo. J Biomech 47(12):3056-3063. doi:10.1016/j.jbiomech.2014.06.031

24. Grässel D, Prescher A, Fitzek S, Keyserlingk DG, Axer H (2005) Anisotropy of human linea alba: a biomechanical study. J Surg Res 124:118-125. doi:10.1016/j.jss.2004.10.010

25. Hakkinen K, Hakkinen A (1991) Muscle cross-sectional area, force production and relaxation characteristics in women at different ages. Eur J Appl Physiol Occup Physiol 62(6):410-414

26. Maughan RJ, Watson JS, Weir J (1983) Strength and cross-sectional area of human skeletal muscle. J Physiol 338:37-49

27. Narici MV, Roi GS, Landoni L (1988) Force of knee extensor and flexor muscles and cross-sectional area determined by nuclear magnetic resonance imaging. Eur J Appl Physiol Occup Physiol 57(1):39-44

28. Podwojewski F, Ottenio M, Beillas P, Guerin G, Turquier F, Mitton D (2013) Mechanical response of animal abdominal walls in vitro: evaluation of the influence of a hernia defect and a repair with a mesh implanted intraperitoneally. J Biomech 46(3):561-566. doi:10.1016/j.jbiomech.2012.09.014

29. Podwojewski F, Ottenio M, Beillas P, Guerin G, Turquier F, Mitton D (2014) Mechanical response of human abdominal walls ex vivo: effect of an incisional hernia and a mesh repair. J Mech Behav Biomed Mater 38:126-133. doi:10.1016/j.jmbbm.2014.07. 002

30. Axer H, von Keyserlingk DG, Prescher A (2001) Collagen fibers in linea alba and rectus sheaths. J Surg Res 96(2):239-245. doi:10.1006/jsre.2000.6071 